\begin{tabular}{|c|c|c|}
\hline \multicolumn{3}{|c|}{$\begin{array}{l}\text { OPEN } \text { ठे ACCESS Freely available online } \\
\text { http://www.banglajol.info/index.php/BJID/index } \\
\text { Perspective }\end{array}$} \\
\hline Bangladesh Jc & al of Infectious Diseases & \\
\hline $\begin{array}{l}\text { October 2020, Volume } \\
\text { ISSN (Online) 2411-670X }\end{array}$ & ber Suppl_2, Page S67-S68 & \\
\hline ISSN (Print) 2411-4820 & DOI: https://doi.org/10.3329/bjid.v7i00.50167 & vasumes numbers \\
\hline
\end{tabular}

\title{
Demerits of Remdesivir: An Unseen Trouble
}

\author{
Sundus Nasim ${ }^{1}$, Sohail Kumar ${ }^{2}$, Dua Azim ${ }^{3}$, Areej Haider Hashmi ${ }^{4}$, Muhammad Taha Nasim ${ }^{5}$
}

${ }^{1}$ Undergraduate Student (MBBS), Dow University of Health Sciences, Karachi, Sindh State, Pakistan; ${ }^{2}$ Undergraduate Student (MBBS), Dow University of Health Sciences, Karachi, Sindh State, Pakistan; ${ }^{3}$ Undergraduate Student (MBBS), Dow University of Health Sciences, Karachi, Sindh State, Pakistan; ${ }^{4}$ Undergraduate Student, Bachelor of Arts (BA) in Global Public Health, University of Virginia College of Arts and Sciences, USA; ${ }^{5}$ A-levels Student, Karachi Grammar School (College Section), Karachi, Sindh State, Pakistan

[Received: 17 August 2020; Accepted: 28 September 2020]

\begin{abstract}
Remdesivir is an investigational antiviral agent available for COVID-19 therapy. Even though its efficacy has been proven through various clinical trials, the evidence is still scarce. The side effects of remdesivir are highlighted in this paper and should be kept in mind during its use. Moreover, the availability of this drug is limited, and we fear an impending shortage of the said medicine in the near future. Thus through this letter we hope to increase awareness regarding this potentially lifesaving medicine. [Bangladesh Journal of Infectious Diseases, October 2020;7(suppl_2):S67-S68]

Keywords: Antiviral; remdesivir; COVID-19; drug; pandemic

Correspondence: Sundus Nasim, Undergraduate Student (MBBS), B-255, Block N, North Nazimabad, Karachi, Pakistan.

Email: sundusnasim9@ gmail.com, contact number: +923412505475.

Conflict of interest: The author declared no conflicts of interest.

Funding agency: This letter did not receive any specific grant from funding agencies in the public, commercial or not-for-profit sectors.

Contribution to authors: All Authors have done write up.

How to cite this article: Nasim S, Kumar S, Azim D, Hashmi AH, Nasim MT. Demerits of Remdesivir: An Unseen Trouble. Bangladesh J Infect Dis 2020;7(suppl_2):S67-S68

Copyright: (2020. Nasim et al. Published by Bangladesh Journal of Infectious Diseases. This article is published under the Creative Commons CC BY-NC License (https://creativecommons.org/licenses/by-nc/4.0/). This license permits use, distribution and reproduction in any medium, provided the original work is properly cited, and is not used for commercial purposes.
\end{abstract}

\section{Introduction}

The coronavirus disease (COVID-19) is a highly contagious respiratory illness caused by severe acute respiratory coronavirus 2 (SARS-CoV-2). The havoc caused by this disease led to it being identified by the World Health Organization (WHO) as a public health emergency of global concern on January 30, 2020 and later as a pandemic on March 11, 2020. Following the surge in the rate of casualties, various clinical trials were initiated to explore potential treatment strategies. Our interest was piqued upon reading an article by Khan TM, in which preventive and control measures against SARS-CoV-2 are comprehensively described ${ }^{1}$. However, this article did not stress upon the potential therapies and consequences of their use against COVID-19. Thus, through this letter, we aim to highlight the recent 
concerns surrounding one of the antiviral drugs, remdesivir.

\section{Remdesivir Drug}

Remdesivir, an RdRp inhibitor, is a broad-spectrum antiviral agent originally synthesized by the Gilead Sciences to treat Ebola virus ${ }^{2}$. Encouraged by the promising role of remdesivir in combatting Ebola, compassionate use of intravenous remdesivir for treatment of COVID-19 patients was initiated in the United States. Favorable treatment results led people to believe that this drug has the potential to eradicate the virus ${ }^{1}$.

\section{Different Clinical Trials}

However, clinical trials regarding the use of remdesivir in COVID-19 seem to be rather inconclusive. In a cohort of hospitalized patients with severe COVID-19, compassionate use of remdesivir resulted in clinical improvement in 68\% of the patients ${ }^{3}$. Nevertheless, robust trials are required to establish a definitive view regarding its clinical efficacy, as mentioned by Ko et $\mathrm{al}^{2}$.It is also imperative to mention that the use of remdesivir is limited due to a multitude of side effects. These include rashes, diarrhea, elevated liver enzymes, and hypotension. Furthermore, the adverse effects were found to be more common in patients on mechanical ventilation. Septic shock, multiple organ dysfunction, and premature renal failure with elevated transaminases were also observed ${ }^{4}$.

\section{Demerits of Remdesivir}

Following remdesivir's Emergency Use Authorization (EUA) by the Food and Drug Administration (FDA) in the United States, a new concern arose regarding its limited availability and distribution disparity. Evidence from Mumbai, India also reported widespread shortage of remdesivir and tocilizumab earlier this month ${ }^{5}$. In addition, Pakistan, a resource-restricted country, is already facing acute scarcity of COVID medicines including tocilizumab, dexamethasone, and even multivitamins. This has led to Pakistani government officials expressing concerns regarding the hoarding of medicines during the pandemic ${ }^{6}$. This raises suspicions that Pakistan may face a similar dilemma in terms of remdesivir in the upcoming months.

Another major concern regarding the reduced availability of novel treatment options is racial disparity when providing these medicines to the general public. Sarpatwari et $\mathrm{al}^{7}$ hypothesize that the availability of remdesivir could be difficult for certain populations, including Blacks and Hispanics, which comprise of nearly half of the hospitalized COVID-19 patients. Such disparities could give rise to widespread resentment among minorities throughout various low-income countries that are notorious for prior occurrence of such incidences.

This warrants the need for a transparent distribution system. We suggest that the distribution of remdesivir should be based on infection statistics from varied regions. Considering the changing dynamics of the outbreak, this strategy should also be modifiable. No discrimination concerning age or ethnicity should be tolerated to enable a transparent outcome. The strategy should be designed to avoid a rapid influx of patients at facilities recognized or believed to have access to the drug.

\section{Conclusion}

In conclusion, this broad-spectrum antiviral agent may be a solution to tackle this ongoing SARSCoV-2 pandemic. However, following its increased demand, we fear that the disparity between need and supply will intensify. While we advise clinicians to proceed with caution when using this drug, we would also like to emphasize the need for a well-structured plan to ensure sufficient supply in order to avoid any future challenges.

\section{References}

1. Khan TM. Preventive and Control Measures of COVID-19 Patients: A Review. Bangladesh Journal of Infectious Diseases. 2020; 7(suppl_1):S41-4

2. Ko WC, Rolain JM, Lee NY, Chen PL, Huang CT, Lee PI, et al. Arguments in favour of remdesivir for treating SARS-CoV2 infections. Int J Antimicrob Agents. 2020;55(4):105933

3. Amirian ES, Levy JK. Current knowledge about the antivirals remdesivir (GS-5734) and GS-441524 as therapeutic options for coronaviruses. One Health. 2020;9:100128

4. Grein J, Ohmagari N, Shin D, Asperges E, Castagna A, Feldt $\mathrm{T}$, et al. Compassionate Use of Remdesivir for Patients with Severe Covid-19. N Engl J Med. 2020;382(24):2327-36

5. Remdesivir shortage: Patients' families run around for help. The Times of India. 2020. Available at: https://timesofindia.indiatimes.com/city/mumbai/remdesivirshortage-patients-families-run-around-for-

help/articleshow/76780181.cms [Accessed 28 July 2020].

6. Hoarding leads to acute medicines shortage. The Express Tribune. 2020. Available at: https://tribune.com.pk/story/2241511/1-hoarding-leads-acutemedicines-shortage. [Accessed 28 July 2020].

7. Sarpatwari A, Kaltenboeck A, Kesselheim AS. Missed Opportunities on Emergency Remdesivir Use [published online ahead of print, 2020 Jun 24]. JAMA. 2020;10.1001/jama.2020.11932. doi:10.1001/jama.2020.11932 